\title{
KARAYOLU İLE TEHLİKELİ MADDE TAŞIMACILIĞI İÇİN COĞRAFİ BİLGİ SİSTEMİ DESTEKLİ ÇEVRESEL RİSK ANALİZí
}

\author{
Serhan KARABULUT ${ }^{\mathbf{1}}$, Ebru Vesile ÖCALIR-AKÜNAL ${ }^{2}$ \\ ${ }^{1}$ Ulaştırma Ağır Oto Tabur Komutanlığı, 2'nci Ordu Komutanlığı, Diyarbakır \\ ${ }^{2}$ Gazi Üniversitesi, Mimarlık Fakültesi, Şehir ve Bölge Planlama Bölümü, Ankara \\ karabulut03@yahoo.com, ebruocalir@gazi.edu.tr
}

(Geliş/Received: 25.06.2014; Kabul/Accepted: 27.07.2015)

ÖZET

\begin{abstract}
Karayolu ile tehlikeli madde taşımacılığı hem birçok farklı aktörü içinde barındırması hem de her birinin farklı bir amacı bulunması sebebiyle özel bir taşıma türüdür. Bu çalışmada, akaryakıtların karayolu ile taşınması esnasında çevresel risklerin değerlendirilebilmesi için bir çevresel risk analiz modeli geliştirilmiştir. Geliştirilen model ile kaza durumunda olumsuz etkilenen çevresel öğeler (su ortamı, toprak ortamı ve özellikli alanlar) analiz edilebilmektedir. Modeli uygulama ve geliştirme aşamasında büyük ölçekli uygulamaları mümkün kılmak için Coğrafi Bilgi Sistemi (CBS)'den destek alınmıştır. Çalışma kapsamında tehlikeli madde türü olarak akaryakıt (benzin, motorin) ve LPG'nin karayolu ile taşıması incelenmiştir. Analitik Hiyerarşi Prosesi (AHP) kullanılarak model kapsamında incelenen her bir çevresel kriterin öncelik ağırlıkları bulunarak İzmir, Manisa, Aydın, Muğla, Denizli karayolu ağında modellerin uygulanmasına geçilmiştir. Uygulamada belirlenen kriterlere göre en uygun güzergâhın tespit edilmesi sağlanmıştır.
\end{abstract}

Anahtar Kelimeler: Risk analizi, Analitik Hiyerarşi Prosesi (AHP), tehlikeli madde, akaryakıt, CBS

\section{GEOGRAPHICAL INFORMATION SYSTEM BASED ENVIRONMENTAL RISK ANALYSIS FOR ROAD TRANSPORTATION OF HAZMATS}

\begin{abstract}
Road transportation of hazmats is special since it requires consideration of various actors who pursue different goals. In this study, an environmental risk analysis model is developed to help assess environmental risks for fuel products shipments. The study proposes a model to analyse the environmental consequences of accidents on the basis of the environmental elements, such as water element, soil element, and featured areas. In order to make large-scale implementations possible, GIS are utilized when using the existing models as well as during the development of the environmental risk analysis model. Transportation of liquid fuel (gasoline and diesel) and LPG are chosen as the main focus of this analysis. The priority weights of each environmental criteria entered into the model are calculated by using Analytical Hierarchy Process (AHP) before risk models are implemented in the road network of İzmir-Manisa-Aydın-Mugla-Denizli. The most convenient route according to the criteria set is determined after case study.
\end{abstract}

Keywords: Risk analysis, Analytical Hierarchy Process (AHP), hazmat, fuel, GIS

\section{GIRIŞ (INTRODUCTION)}

Tehlikeli maddeler, üretilmesi, depolanması ve taşınmaları sırasında toplumu ve çevreyi belirli bir riske maruz bırakmaktadır. Neredeyse tüm tehlikeli madde taşımaları bu maddelerin üretildiği, depolandığı veya dağıtımı yapıldığı sabit bir tesis olan kaynak noktasından, tehlikeli maddenin ihtiyaç duyulduğu yer olan bir ya da daha fazla varış noktasına taşınmaktadır. Bu durumda iki nokta arasında istenilen kriterlere göre en uygun güzergâhı seçme problemi ile karşı karşıya kalınmaktadır. Güzergâhın belirlenmesinde hangi faktörlerin ağırlıklı olarak ele alınacağı resmi otoriteler ya da taşıyıcılar 
açısından değişiklik göstermekle beraber risk faktörleri ile ekonomik faktörlerin birbiri ile çatışması bu süreci daha karmaşık bir hale getirmektedir [1]. Karayolu ile tehlikeli madde taşımacılı̆̆ı hem birçok farklı aktörü içinde barındırması hem de her birinin farklı bir amacı bulunması sebebiyle özel bir taşıma türüdür. $\mathrm{Bu}$ yüzden tehlikeli madde taşımacılığ genellikle çözümü karmaşık olan çok aktörlü ve çok amaçlı bir problemdir. Tehlikeli madde taşımacılığ güzergâh seçiminde çok amaçlı problemin doğası gereği genellikle her bir amacı optimize eden tek güzergâh tanımlamak neredeyse imkânsızdır.

Dünyada yılda 450 milyon ton tehlikeli madde taşınmaktadır. $\mathrm{Bu}$ taşımanın \% 63,3'ü karayolu taşımacılığı ile gerçekleşmektedir [2]. Amerika'da 2010 yılında yayınlanmış bir rapora göre ulaşım modu göz önüne alındığında taşınan tehlikeli madde miktarının \%53,9'luk kısmı karayolu ile taşınmaktadır [3]. Türkiye'de ise yılda yaklaşık 750000 ton tehlikeli madde yaklaşık 15000 araçla karayolu ile taşınmaktadır [2]. Türkiye'de de karayoluyla taşınan tehlikeli madde miktarının diğer dünya devletleri ile aynı seviyelerde olduğu tahmin edilmektedir.

Tehlikeli madde taşımacılığı için risk analizi ile ilgili olarak bu güne kadar hazırlanmış birçok bilimsel çalışma mevcuttur [4-15]. Ayrıca, birçok çalışmada [16-21] CBS tehlikeli madde taşımacılığında risk analizi için kullanılmıştır. Yapılan çalışmalar genel olarak taşıma mesafesi ve maliyetini en aza indirme ve kaza durumunda etkilenen kişi sayısının minimize edilmesi konuları üzerinedir. Bunun yanında, tehlikeli maddelerin çevresel risk değerlendirmesini ele alan çalışmalar [22-24] da bulunmaktadır. Özetle bütün bu çalışmalar, tehlikeli madde taşımacılığında risk değerlendirmesi konusunda literatürde belirli bir eksikliği gidermektedir. Ancak tehlikeli madde taşımacılığında çevrenin göreceği zararın minimize edilmesiyle ilgili bir risk modeli ihtiyac1 ortaya çıkmaktadır.

$\mathrm{Bu}$ çalışmada, literatürde tanımlanmış mevcut risk analiz modellerinin uygulanmasının yanında akaryakıtların karayolu ile taşınması esnasında çevresel risklerin değerlendirilebilmesi için çevresel risk analiz modeli geliştirilmiştir. Çalışmanın ana amacı, CBS yardımıyla tehlikeli madde taşımacılığı için risk analizi yaparak güzergâhları kıyaslamak, tehlikeli maddelerin çevresel risk faktörlerini belirleyerek bir çevresel risk analiz modeli geliştirmektir.

Türkiye'de tüketilen tehlikeli maddelerin yaklaşık \%80'ini akaryakıt ve LPG ürünleri oluşturmaktadır [19]. 2012 yilında benzin, motorin ve LPG toplamından oluşan otomotiv yakıtları toplam tüketimi 18,2 milyon ton olarak gerçekleşmiştir [25]. $\mathrm{Bu}$ sebepten dolayı çalışmada akaryakıt (benzin, motorin) ve LPG'nin karayolu ile taşıması incelenmiştir. Mevcut modellerin uygulanması ve çevresel risk analiz modelinin geliştirilmesi aşamasında CBS yazılımı olarak MapInfo Professional 10.5 kullanılmıştır. Mevcut modellerin ve geliştirilen çevresel risk analiz modelinin uygulanarak sonuçların değerlendirmesi amacıyla uygulama alanı olarak İzmir, Manisa, Aydın, Muğla, Denizli karayolu seçilmiştir. Uygulama sonucunda aynı bölgeye uygulanan farklı tehlikeli madde türleri ile farklı risk analiz modellerinin sonuçları kıyaslanmıştır.

\section{TEHLİKELİ MADDE TAŞIMACILIĞINDA RİSK DEĞERLENDİRMESİ (RISK ASSESSMENT FOR HAZMAT TRANSPORTATION)}

\subsection{Literatür Taraması (Literature Survey)}

Genel anlamda tehlikeli madde taşımacılığında risk tanımı iki bileşenle ortaya konmaktadır. Bunlar: (i) istenmeyen olumsuz bir olayın meydana gelme olasılığı ve (ii) olumsuz olayın sonuçlarıdır [26]. Geleneksel risk tanımına göre, sadece bir olay için ortaya çıkan risk $(R)$, bu olayın meydana gelme olasılığı $(P)$ ile bu olayda ortaya çıkan sonucun $(C)$ çarpımına eşittir. Buna göre risk Eşitlik.1'de sunulduğu gibi tanımlanır [14].

$R=P . C$

Tehlikeli madde hareket halindeyken yol boyunca çevresi üzerinde oluşturduğu bir risk vardır. Bu risk aynı şekilde bir olaya ait $P$ olasılığ 1 ile $C$ sonucunu içeren $n$ birim yol bölümünden oluşur. $\mathrm{Bu}$ durumda beklenen risk değeri Eşitlik.2'de belirtilmiştir [11].

$R=\sum_{i=1}^{n} P_{i} C_{i}$

Geleneksel risk modeli olarak adlandırılan bu modeli, olayın meydana gelme olasılığı ile bu olayda ortaya çıkan sonuçların yol boyunca normal dağıldığı varsayımına dayanır. Geleneksel risk modeli en yaygın kullanılan model olmasına karşın literatürde birçok farklı risk modeli önerilmiştir. Bu modeller Tablo 1'de sunulmuştur.

Büyük ölçekli bir uygulamanın yapıldığı bu çalışmada; riske maruz kalan nüfusun ortaya konması, her yol kesimi için kaza riskinin hesaplanması ve bu her iki faktörün de göz önüne alınması maksadıyla Nüfusa Etki Risk Modeli, Olaylı Kaza Olma Olasılığı ve Toplumsal Risk Modeli kullanılmıştır. Ayrıca, riske maruz kalan çevresel öğelerin ortaya konması maksadıyla geliştirilen Çevresel Risk Analiz Modeli uygulanmış ve model sonuçlarını güzergâh uzunluğu ile karşılaştırma açısından en kısa yol algoritması kullanılmıştır.

Nüfusa etki risk modeli, güzergâh üzerinde belirli bir alanda yaşayan insanları potansiyel risk altında kabul eden bir risk modelidir. Güzergâh üzerinde bulunan 
Tablo 1. Tehlikeli madde taşımacılığında risk analiz modelleri (Risk models for hazmat transportation)

\begin{tabular}{|l|l|l|}
\hline Risk Analiz Modeli & Hesaplama Kriteri & Literatürdeki Yeri \\
\hline Nüfusa Etki Risk Modeli & Etki alanı içerisindeki insan sayısı & $6,7,15,18$ \\
\hline Toplumsal Risk Modeli & $\begin{array}{l}\text { Etki alanı içerisindeki insan sayısı } \\
\text { Yol kesimindeki kaza sayısı }\end{array}$ & $5,11,15,17,18,26$ \\
\hline Olaylı Kaza Olma Olasılığı & Yol kesimindeki kaza sayısı & $4,8,15,18$ \\
\hline Algılanmış Risk Modeli & $\begin{array}{l}\text { Düşük olasılıklı ağır sonuçlu kazanın beklenen } \\
\text { zarar değeri }\end{array}$ & 8,11 \\
\hline Koşullu Risk Modeli & İlk kazanın beklenen zarar değeri & $9,10,27,28$ \\
\hline $\begin{array}{l}\text { En Çok Nüfusa Etki Risk } \\
\text { Modeli }\end{array}$ & Etki alanı içerisindeki büyük çaplı insan sayısı & 13,29 \\
\hline Beklenen Faydasızlık & Büyük çaplı kaza riski & 13,29 \\
\hline Ortalama - Varyans Modeli & Riske maruz kalan insan sayısının varyansı & 10 \\
\hline Talep Tatmin Modeli & İki nokta arasındaki taşıma sayısı & 29 \\
\hline Zaman Etkili Risk Modeli & Riske maruz kalan insan sayısı ve taşıma süresi & 30 \\
\hline $\begin{array}{l}\text { Kümülatif Ağırlık ve Puanlama } \\
\text { Modeli }\end{array}$ & $\begin{array}{l}\text { Riske maruz kalan insan sayısı, trafik } \\
\text { sıkışıklığı ve güvenliği }\end{array}$ & 31,32 \\
\hline $\begin{array}{l}\text { Çevresel Risk Analiz Modeli } \\
\text { Etki alanı içerisindeki çevresel öğeler }\end{array}$ & $\begin{array}{l}\text { Bu çalışmada } \\
\text { önerilmektedir }\end{array}$ \\
\hline
\end{tabular}

olaylı kazanın meydana geldiği bir $c$ noktası merkez kabul edilerek etrafındaki ( $\lambda$ ) yarıçaplı dairesel alan potansiyel risk altında kabul edilerek tehlike alanı olarak adlandırılır. Tehlikeli alanı yarıçapı $(\lambda)$, taşınan tehlikeli maddenin türüne göre farklılık göstermektedir. $m$ tehlikeli madde türüne ait $s$ yol segmentinde ilerleyen bir araca ait tehlikeli alanı yarıçapı $(\lambda)$ içinde kalan nüfusa etki değeri Eşitlik. 3 'de gösterilmiştir [18].

$\bar{C}_{s, m}=\sum_{s=1}^{r} d_{s}\left(2 l_{s} \lambda_{m}+\pi \lambda_{m}^{2}\right)$

Olaylı kaza olma olasılı̆̆ risk tanımına göre olaylı kaza olma olasılığı $\left(R_{\text {ip }}\right)$, o yola ait her bir yol kesiminin uzunluğu $\left(l_{s}\right)$ ile olaylı kaza olma olasılığ $\left(p_{s}\right)$ çarpım değerlerinin toplamına eşittir. Buna göre olaylı kaza olma olasılığı Eşitlik. 4'de gösterilmiştir [4].

$R_{\text {ip }}=\sum_{s=1}^{r} l_{s} p_{s} \quad p_{s}=\frac{k_{s}}{K}$

Toplumsal risk modeli, olayı kaza olma olasılığı ile kaza sonucu etkilenecek nüfus değerinin çarpımı şeklinde ifade edilmektedir [11]. $\mathrm{Bu}$ durumda, $m$ tehlikeli madde türüne ait $s$ yol segmenti etrafindaki tehlike alanı içerisinde yaşayan nüfus $C_{s, m}$ ile olaylı kaza olma olasılığını ( $R_{i p}$ ) açık olarak ifade edersek, toplumsal risk değeri $\left(R_{s r}\right)$ Eşitlik. 5'de gösterildiği şekilde olur.

$R_{s r}=\left(\sum_{s=1}^{r} l_{s} p_{s} d_{s}\right) \pi \lambda_{m}^{2}$

\section{2 Önerilen Çevresel Risk Analiz Modeli (Proposed} Environmental Risk Model)

Çevresel risk; sonuçları, insan sağlığı, yaşam koşulları ve çevreyi, toprağı, yüzeysel suları, yer altı suyunu, havayı, iklimi, flora ve faunayı, biyolojik çeşitliliği, toplum yapısını, binaları, manzarayı, şehrin görüntüsünü, kültürel mirası ve bu bileşenler arasındaki ilişkiyi etkileyen risk olarak tanımlanmaktadır [22]. $\mathrm{Bu}$ çalışmada önerilen çevresel risk analiz modeli, akaryakıt ve LPG'nin kar(Gyọllbyla taşınması esnasında yarattıkları kirlilik sonucunda; yeryüzündeki su kaynaklarının zarar görmesi, doğal bitki örtüsünün tahribi, verimli tarım alanlarının çölleşmesi, ormanların yok olması, turizm alanlarının zarar görmesi ve doğa koruma alanlarının kirletilmesini önleyecek güzergâhların tespit edilmesini amaçlamaktadır.

Bir olayın meydana gelme olasılığı ile bu olayda ortaya çıkan sonuçların yol boyunca normal dağıldığı varsayımına dayanan geleneksel risk tanımından hareketle çevresel risk analiz modeli ifade edilmiştir. Buna göre beklenen çevresel risk değeri $(C ̧ R)$, kaza olma olasılığı $\left(P_{S}\right)$ ile çevrede meydana gelen zararın (C) çarpımı olarak Eşitlik. 6'da belirtilmiştir [33].

ÇR $=P_{S} C$

Geliştirilen çevresel risk analiz modelinde Eş. 6'daki çevrede meydana gelen zarar $(C)$, kümülatif ağırlık ve puanlama modelinden uyarlanarak ortaya konulmuştur [31,32]. Yapılan çalışmalarda yol güvenliğini ortaya koyan güzergâha ait maliyet 
fonksiyonu Eşitlik 7'de sunulan kümülatif ağırlık ve puanlama modeli ile hesaplanmıştır [31,32].

Güzergah Maliyeti $(R)=\sum_{c=1}^{n_{c}}\left(w_{c} \sum_{c f=1}^{n_{c f}} w_{c f} s_{c f}\right)$

Geliştirilen çevresel risk analiz modelinde benzer bir şekilde çevresel zarar $(C)$, bu basit maliyet modelinden uyarlanmış fakat puanlama fonksiyonu yerine faktörlerin alansal hesaplanması olarak ifade edilmiştir. Bir olayın meydana gelme olasılığı $\left(P_{S}\right)$ da, belirlenen yol kesiminde kaza olma olasılığı ile ortaya konulmuştur. Bu durumda çevresel risk analiz modeli Eşitlik 8'de sunulduğu gibi ortaya konulmuştur.

$C ̧ R=\frac{k_{s}}{K}\left(\sum_{k=1}^{n_{k}}\left(w_{k} \sum_{k_{f}=1}^{n_{f}} w_{k f} A_{s, m}\right)\right)$

$k_{s}=\mathrm{S}$ yol kesiminde meydana gelen kaza sayısı

$K=$ toplam kaza sayıs

$k=$ kriter

$n_{k}=$ kriter sayıs 1

$w_{k}=$ kriter ağırlığ 1

$k_{f=} k$ kriteri altında bulunan faktör

$n_{f=} k$ kriteri altında bulunan faktör sayısı

$w_{k f}=k$ kriteri altında bulunan faktör ağırlığ 1

$A_{s, m}=m$ teh. madde türüne ait s yol kesimi tehlike alanında çevresel faktörler alanı

Çevresel riskin hesaplanmasında istenmeyen sonuç çevresel öğelerdeki kirlenme yani riske maruz kalan çevresel öğeler; su ortamı, toprak ortamı ve özellikli alanlardaki kirlenmedir. Her bir kriter risk kaynaklarından olumsuz etkilendiği için ayrı ayrı hesaplanarak toplam zarar elde edilmiştir. Çevrede meydana gelen zararın risk tanımının diğer bileşeni olan kaza olma olasılığı ile çarpımı sonucunda çevresel risk değeri hesaplanır.

Geliştirilen çevresel risk analiz modeli ile çevrenin zarar görme riskinin minimize edilmesi ve tehlikeli madde taşımacılığında çevresel faktörler açısından en uygun güzergâhın belirlenmesi sağlanacaktır.

\section{TEHLIKELİ MADDE TAŞIMACILIĞI İÇIN GÜZERGÂH ALTERNATIFLERININ DEĞERLENDİIILMESİ (EVALUATION OF ROUTE ALTERNATIVES FOR HAZMAT TRANSPORTATION)}

Çalışma kapsamında önerilen Çevresel Risk Analiz Modeli ile bir örnek alanda (Afyonkarahisar, Kütahya, Uşak illeri hariç Ege Bölgesi), iki farklı tehlikeli madde türü için uygulama yapılmıştır. Elde edilen sonuçlar, literatürde mevcut olan modellerin uygulama sonuçları ile karşılaştırılmış ve sonuçlar grafikler halinde ortaya konmuştur.

\subsection{Uygulama Alanı (Study Area)}

Karayoluyla tehlikeli madde taşımacılığında belirtilen amaçlara ulaşmak için uygulama alanı olarak İzmir, Manisa, Aydın, Muğla, Denizli karayolu ağı seçilmiştir. Uygulama alanını gösteren harita Şekil 1 'de sunulmuştur.

Uygulama alanı karayolu ağı açısından incelendiğinde, otoyol, devlet ve il yolları uzunlukları toplamı $5357 \mathrm{~km}$ olup, mevcut karayolu ağı toplam 183 yol kesiminden oluşmaktadır. Uygulama alanı içinde 16 otoyol kesimi, 57 devlet yolu ve 110 il yolu kesimi bulunmaktadır. Modellerin uygulanması aşamasında uygulama alanı içerisinde yer alan beş ildeki toplam 4 LPG tesisi, 2 akaryakit tesisi ile 815 akaryakıt - LPG istasyonu arasındaki karayolu ile yapılan taşımalar göz önüne alınmıştır.

Çalışmada kullanılan nüfus bilgileri, 31 Aralık 2010 tarihi itibariyle Adrese Dayalı Nüfus Kayıt Sisteminden elde edilen nüfus bilgileridir. Uygulama alanı içinde tehlikeli maddelerin taşınmasına izin verilmeyen 3 adet tünel (Bunlar; Karşıyaka 1, Karşıyaka 2, 75.Yıl Selatin Tünelleridir) hesaplamalarda göz önüne alınmıştır.

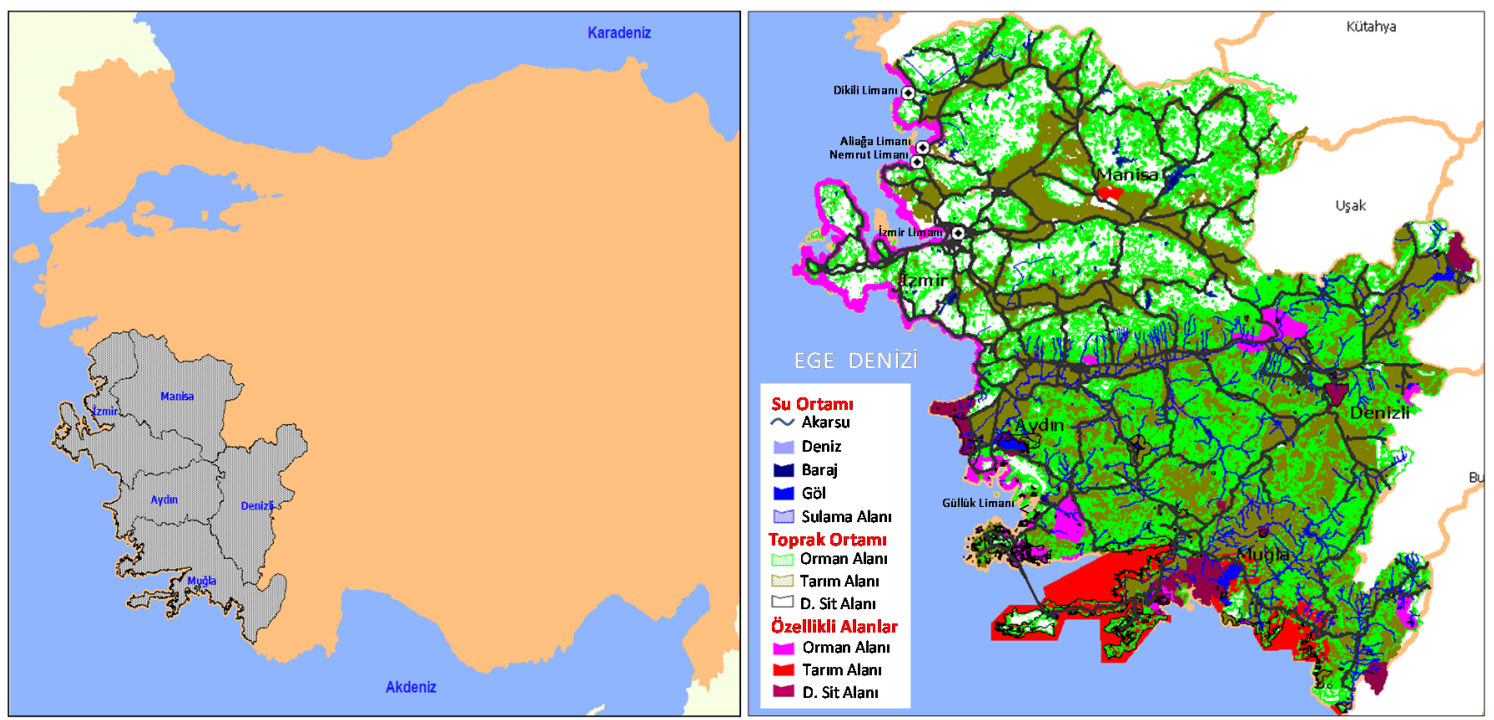

Şekil 1. Uygulama alanı (Study area) 
Kaza verisi olarak, Emniyet Genel Müdürlüğü Trafik Eğitim ve Araştırma Daire Başkanlığı'ndan temin edilen kontrol kesim noktalarına göre 2010 yılı trafik kaza verileri kullanılmıştır. Çevresel öğelere ait veriler, uygulama alanı içerisinde yer alan İzmir, Manisa, Aydın, Muğla ve Denizli illerinin çevre düzeni planları iki planlama bölgesi olarak Çevre ve Şehircilik Bakanlığı'ndan sayısal veri tabanı şeklinde temin edilmiştir.

\subsection{Analiz Metodu (Analysis Method)}

Çalışmada risk analizi için gerekli verileri oluşturmak, düzenlemek, görselleştirmek ve analiz etmek amacıyla MapInfo Professional 10.5 CBS yazılımı kullanılmıştır. Ayrıca MapBasic yazılımı ile coğrafi bilgi sistemine hesaplanan risk değerlerine göre rotalama yapma, her bir yol kesiminin istenilen amaca uygun risk değerlerinin hesaplanması ve belirtilen etki alanına göre risk değeri hesaplama ve rotalama yetenekleri eklenmiştir.

Çalışma kapsamında etki alanı, en yaygın kullanılan tehlike çemberi modeli ile tanımlanmıştır [11,34]. CBS yazılımında bir nesne etrafında bölge oluşturma araçları kullanılarak yol segmentleri etrafında yarıçap değeri girilerek tampon oluşturulmuştur. Taşınan tehlikeli madde özelliklerine bağlı olarak değişim gösteren etki yarıçapı, çalışmada incelenen tehlikeli madde türleri için tehlikeli maddeler ile ilgili bilgileri ihtiva eden Emergency Response Guidebook (2008)'tan alınmıştır [35]. Benzin/motorin ile LPG'nin tehlike özellikleri farklı olduğundan iki farklı etki alanı tanımlanmıştır: Benzin, motorin taşımaları analizi için 800 metre yarıçaplı etki alanı, LPG taşımaları analizi için 1600 metre yarıçaplı etki alanı tanımlaması yapılmıştır [35].

Uygulama alanı içerisinde kalan mevcut karayolu ağı için çıkış-varış noktaları arasındaki tüm taşıma alternatifleri değerlendirilmiştir. En kısa yol, çıkış ile varış noktası arasındaki kilometre cinsinden en kısa mesafeyi ifade eder. En düşük riskli yol ise her risk modeli için iki nokta arasında toplam risk değerini minimize eden güzergâhı ifade etmektedir. CBS kullanılarak belirlenen (o-d) çifti arasında, risk analizinin yapılması için çalışmada belirlenen amaçlar: en kısa yol, minimum nüfusa etki, minimum kaza olasılığı, minimum toplumsal risk ve minimum çevresel risktir.

\section{3 Çevresel Riskin Hesaplanması (Calculation of Environmental Risk)}

Oluşan riski kalitatif ya da kantitatif olarak ortaya koyabilmek için riski oluşturan risk kaynağı, yol ve etki alanları analiz edilmiştir. Risk kaynağı, taşıma esnasında ortaya çıkan risk incelendiğinden taşınan tehlikeli madde türlerini kapsar [33]. Çalışma kapsamında ele alınan akaryakıt (benzin, motorin) ve
LPG taşıma esnasında oluşan çevresel risklerin kaynağını oluşturmaktadır. Riskin oluştuğu yol, taşımanın yapıldığı mevcut karayolu ağını kapsamaktadır. Risk etki alanları, risk kaynaklarından olumsuz etkilenen çevresel öğelerin belirlenmesi anlamına gelmektedir. Literatürde, riske maruz kalan çevresel öğeler genel olarak su ortamı, toprak ortamı ve ekolojik ortam olmak üzere üç ana grupta toplanmaktadır [33; 36-40]. Çalışma kapsamında ele alınan çevresel kriterlerin tümü iki seviye olarak belirlenmiştir. Belirlenen çevresel faktörlerden tehlikeli madde etki çapı içerisinde kalan bölümleri CBS yardımıyla alansal olarak hesaplanarak kümülatif bir değerlendirme sonucunda risk değeri hesaplanmıştır.

Tablo 2. Ana ve alt kriter ağırlık değerleri (Weighting values for main and sub-criteria)

\begin{tabular}{|c|c|c|}
\hline $\begin{array}{c}\text { Ana Kriter / A Ăırlık } \\
\text { Değeri }\end{array}$ & Alt Kriter & $\begin{array}{l}\text { Ăğırlık } \\
\text { Dĕgeri }\end{array}$ \\
\hline \multirow{5}{*}{$\begin{array}{l}\text { Su Ortamı (A) } \\
0,393 \\
\text { T. } O=0,019<0,1\end{array}$} & Akarsu (A1) & 0,162 \\
\hline & Baraj (A2) & 0,367 \\
\hline & Deniz (A3) & 0,108 \\
\hline & Göl (A4) & 0,151 \\
\hline & $\begin{array}{l}\text { Sulama Alanları } \\
\text { (A5) }\end{array}$ & 0,212 \\
\hline \multirow{3}{*}{$\begin{array}{l}\text { Toprak Ortamı (B) } \\
0,223 \\
\text { T. } O=0,033<0,1\end{array}$} & $\begin{array}{l}\text { Orman Alanları } \\
\text { (B1) }\end{array}$ & 0,156 \\
\hline & $\begin{array}{l}\text { Doğal Sit } \\
\text { Alanları (B2) }\end{array}$ & 0,113 \\
\hline & $\begin{array}{l}\text { Tarım Alanları } \\
\text { (B3) }\end{array}$ & 0,731 \\
\hline \multirow{3}{*}{$\begin{array}{l}\text { Özellikli Alanlar } \\
\text { (C) } \\
0,384 \\
\text { T. } O=0,005<0,1\end{array}$} & $\begin{array}{l}\text { Doğa Koruma } \\
\text { Alanlar1 }(\mathrm{C} 1)\end{array}$ & 0,439 \\
\hline & $\begin{array}{l}\text { Çevre Koruma } \\
\text { Alanları (C2) }\end{array}$ & 0,376 \\
\hline & $\begin{array}{l}\text { Turizm Bölgeleri } \\
\text { (C3) }\end{array}$ & 0,184 \\
\hline
\end{tabular}

Çevresel riske neden olan faktörlerin çok çeşitli olması, hangi kriterin daha önemli olduğu konusunda etkili ve doğru karar vermeyi güçleştirmektedir. Çevresel risk analizi yapılırken çevresel kriterlerin öncelik ağırlıklarının bulunması maksadıyla AHP kullanılmıştır [41,42]. Bunun için çevre konusunda uzman akademik personel ve çeşitli kurumlardaki konuyla ilgili çalışmalar yürüten ve karar verici pozisyonlarda çalışan çevre uzmanlarından oluşan iki farklı gruptan 10 uzman personelin görüşleri alınmıştır. Faktörlerin öncelik ağırlıklarının bulunması amacıyla hiyerarşik model oluşturularak uzmanlarından elde edilen değerlendirmeler sonucu kriterlerin ve alt kriterlerin ikili karşılaştırma matrisleri oluşturulmuştur. İkili karşılaştırma matrisleri, birden fazla kişinin değerlendirmesi ile elde edildiği için yargıların birleştirilmesi açısından değerlendirmelerin geometrik ortalamalarının hesaplanmasıyla elde edilmiştir. Tablo 2'de ana kriter ve alt kriterler ile ikili karşılaştırma matrislerinden 
AKARYAKIT TAŞIMACILIĞI

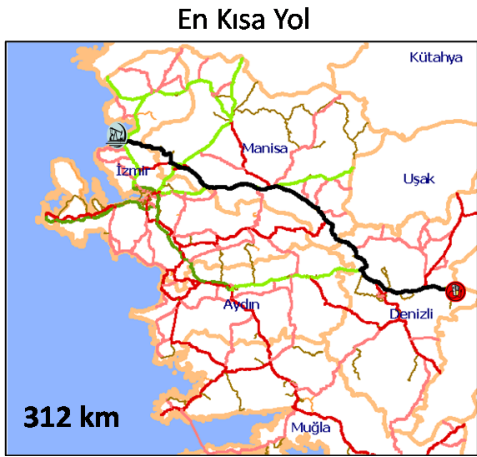

Minimum Toplumsal Risk

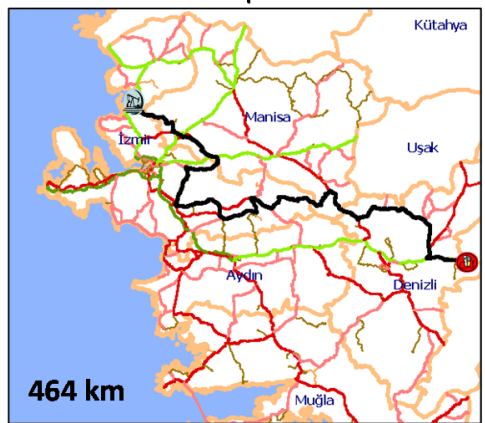

LPG TAŞIMACILIĞI

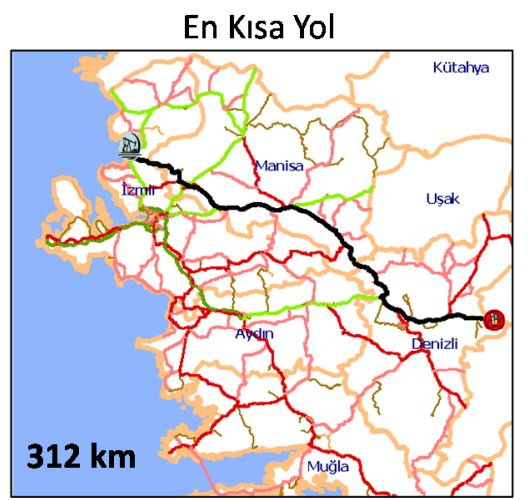

Minimum Toplumsal Risk

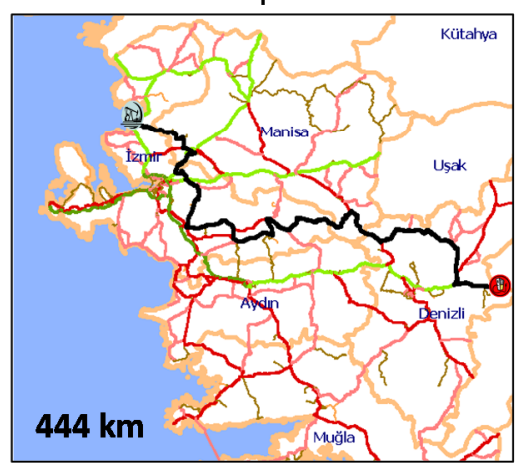

Minimum Nüfusa Etki

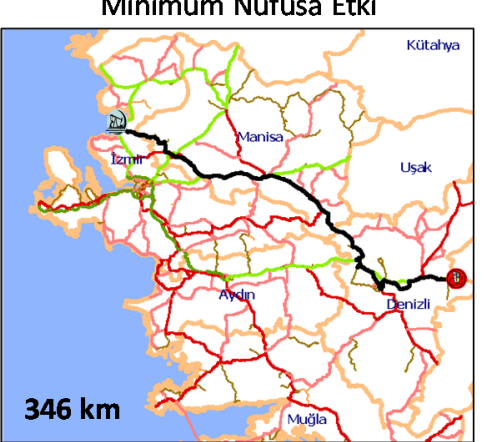

Minimum Çevresel Risk

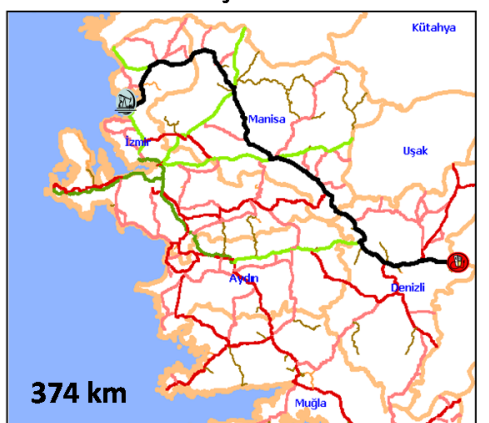

Minimum Nüfusa Etki

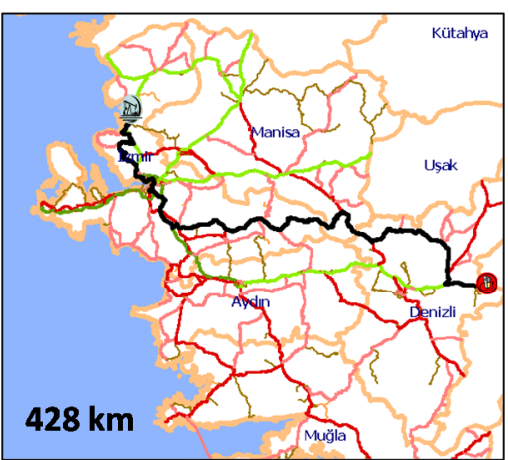

Minimum Çevresel Risk

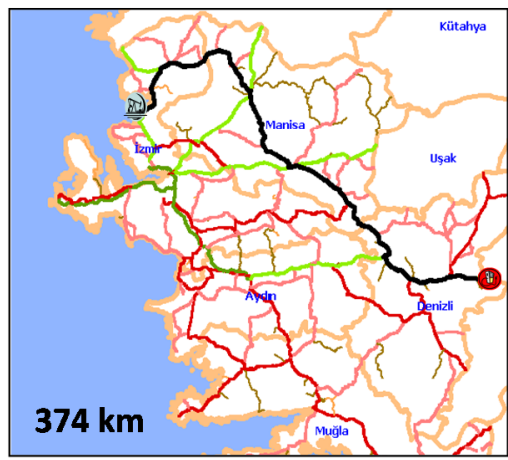

Minimum Olaylı Kaza

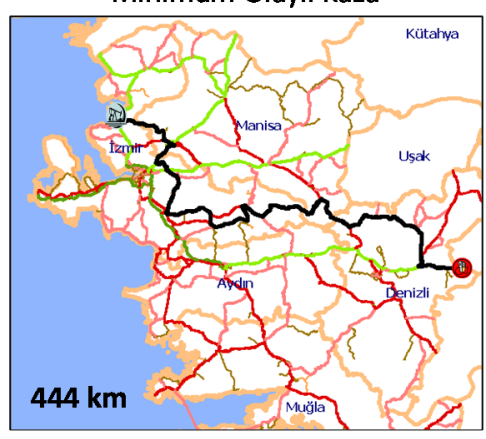

Güzergah Uzunlukları

$$
\begin{array}{ll}
\text { En Kısa Yol } & : 312 \mathrm{~km} \\
\text { Min. Nüfusa Etki } & : 346 \mathrm{~km} \\
\text { Min. Olaylı Kaza } & : 444 \mathrm{~km} \\
\text { Min. Toplumsal Risk } & : 464 \mathrm{~km} \\
\text { Min. Çevresel Risk } & : 374 \mathrm{~km} \\
& \\
\text { 혈) Çıkış noktası } & \text { (di) Varış noktası }
\end{array}
$$

Minimum Olaylı Kaza

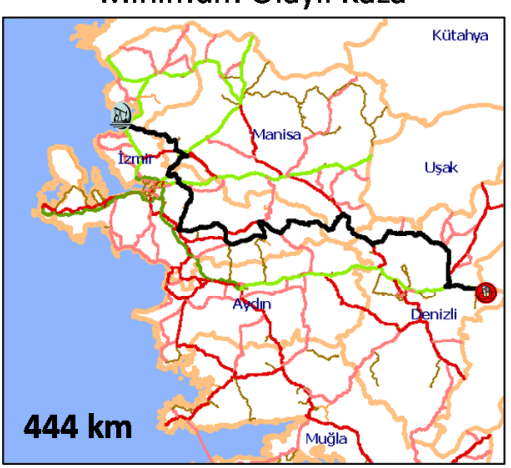

Güzergah Uzunlukları

$$
\begin{array}{ll}
\text { En Kısa Yol } & : 312 \mathrm{~km} \\
\text { Min. Nüfusa Etki } & : 428 \mathrm{~km} \\
\text { Min. Olaylı Kaza } & : 444 \mathrm{~km} \\
\text { Min. Toplumsal Risk } & : 444 \mathrm{~km} \\
\text { Min. Çevresel Risk } & : 374 \mathrm{~km} \\
& \\
\text { 궐 Çııış noktası } & \text { (d) Varış noktası }
\end{array}
$$

Şekil 2. Model sonuçlarına göre Aliağa - Çardak arasındaki akaryakıt ve LPG taşımacılığı için alternatif güzergâhlar (Alternative routes according to model results for fuel and LPG shipment between Aliağa Çardak) 
hesap edilen ağırlık değerleri özet olarak gösterilmiştir.

Elde edilen ağırlık değerleri her bir kriter ile çarpılarak hesaplanan risk değerleri ağırlıklandırılmıştır.

\subsection{Model Sonuçları (Model Results)}

Risk analiz modelleri belirlenen alanda uygulanarak bu modellerin gerçek karayolu ağı üzerindeki etkileri araştırılmıştır. Türkiye'de faaliyet gösteren ikinci büyük rafineri olduğundan Aliağa Rafinerisi çıkış noktası olarak belirlenmiştir. Hem akaryakıt (benzin, motorin) hem de LPG taşımaları için örnek olarak Aliağa - Çardak güzergâhı seçilerek risk analiz modelleri uygulanmış olup Şekil 2.'de yapılan taşımalar gösterilmiştir.

Akaryakıt gönderisi mümkün olan en kısa yoldan gönderilecek olsaydı 312 km'lik bir yol kat etmek gerekecekti. En uzun güzergâh ise $464 \mathrm{~km}$ ile minimum toplumsal risk güzergâhıdır. Minimum toplumsal riski veren güzergâh en k1sa yola göre $\% 49$ daha uzundur. LPG taşımasına ait kaza yapma ihtimalinin en az olduğu güzergâh ile toplumsal riski minimize eden güzergâh aynı olup 444 km'lik bir uzunluğa sahiptir. Herhangi bir kaza halinde çevresel öğelerin en az zarar göreceği güzergâh tercih edilecek olursa 374 km'lik yol kat edilmesi gerekmektedir. Risk analiz modellerine ait sonuçlar incelendiğinde; Akaryakıt ve LPG taşımacılığı modelleri ayrı ayrı ele alındığında, uzaklık ve risk değerlerinin ele alınan modellerde birbirinden farklı olduğu görülmektedir. Sadece, LPG taşımacılığı için minimum olaylı kaza ile minimum toplumsal riski veren güzergâhın aynıdır. Bu iki güzergâha ait hem uzunluk hem de risk değerleri aynıdır.

İki tehlikeli madde türü karşılaştırıldığında en kısa yol güzergâhı ile minimum kaza olasılığı güzergâhının aynı uzaklıkta olduğu görülür. Bunun sebebi en kısa yol ve minimum kaza olasılığı güzergâhları hesaplanırken karayolu ağı etrafına tanımlanan etki yarıçapının hesaba katılmamasıdır. Ancak minimum nüfusa etki, minimum toplumsal risk ve minimum çevresel risk hesaplamalarında karayolu ağı etrafina tanımlanan etki yarıçapına dayalı olarak risk değerleri değişkenlik göstermektedir.

\section{SONUÇLAR VE ÖNERİLER (CONCLUSIONS AND RECOMMANDATIONS)}

\subsection{Sonuçlar (Conclusions)}

Çalışmada tehlikeli madde taşımaları esnasında ortaya çıkan riskin güzergâh seçimi ile azaltılmasına yönelik analiz ortaya konulmuştur. Uygulama sonucunda farklı amaç ve tehlikeli madde türü taşımaları için farklı güzergâhlar ortaya çıkmıştır. Bunun sebebi her yol segmentine ait risk değerinin belirlenen kritere göre farklılık göstermesi ve CBS vasıtasıyla risk değerlerine göre rotalama yapılmasıdır. Uygulama sonucunda ortaya çıkan değerlendirme özetle şu şekildedir;

Herhangi bir amaç için optimum sonucu veren bir güzergahın diğer amaçlar için aldığı risk değeri araştırıldığında, maliyeti en aza indiren güzergâhın yani en kısa yolun aynı zamanda riski en aza indiren güzergâh olmadığı ortaya çıkmıştır.

Aynı çıkış-varış noktası çifti arasında taşınan farklı tehlikeli madde türleri için ortaya çıkan güzergâhların farklı olduğu görülmüştür. $\mathrm{Bu}$ sebepten dolayı tüm tehlikeli madde türleri için riski en aza indiren bir güzergâh tanımlamak gerçekçi ve mümkün değildir.

Herhangi bir çıkış-varış noktası çifti arasındaki minimum riski veren güzergâh belirlenen amaç ve tehlikeli madde türü için bulunabilir.

Geliştirilen çevresel risk analiz modeli matematiksel olarak ifade edilerek altyapısı oluşturulmuş olup belirlenen farklı ya da daha geniş bölgeye uyarlanabilir.

\section{2 Öneriler (Recommendations)}

Türkiye'deki karayoluyla akaryakıt taşımacılığında risk analizi konusunda kısıtlı sayıda çalışma olduğu göz önüne alındığında literatürdeki eksiklik halen devam etmektedir. İleride yapılacak çalışmalara 1 şık tutacak araştırma konuları aşağıda kısaca sunulmuştur:

Literatürde yer alan mevcut diğer risk modelleri kullanılarak veya yeni risk tanımları geliştirilerek bu tip çok amaçlı problemlere alternatif sonuçlar üretilebilir.

Çalışmada belirlenen amaca uygun olarak ortaya çıkan risk değerlerine göre rotalama yapılmıştır. Bunun yanında, ağırlıklandırma yapılarak birleştirilmiş amaçlara göre en az riskli güzergâhı bulmak da mümkündür.

Risk analiz modeli geliştirilirken, yol segmentlerinin geometrik özellikleri, trafik özellikleri ile kritik altyap1 özellikleri gibi detaylar dikkate alınarak modele dâhil edilebilir.

\section{KAYNAKLAR (REFERENCES)}

1. Castillo, J.E.A., Route Optimization For Hazardous Materials Transport, Yüksek Lisans Tezi, International Institute for GeoInformation Science and Earth Observation, Urban Planning and Land Administration, Enschede, The Netherlands, 2004.

2. Alışan, D., "Tehlikeli Kimyasal Maddelerin Taşınması ve Depolanması", Tehlikeli 
Kimyasalların Yönetimi Sempozyumu, Ankara, 257-266, 8-9 Ocak 2009.

3. USDOT (U.S. Department of Transportation), USDOC (U.S. Department of Commerce), Hazardous Materials Transportation 2007 Commodity Flow Survey, Bureau of Transportation Statistics, United States, 2010.

4. Saccomanno, F., Chan, A., "Economic Evaluation of Routing Strategies for Hazardous Road Shipments", Transportation Research Record, No 1020,12-18, 1985.

5. Pijawka, K.D., Foote, S., Soesilo, A., Scanlon, R.D., Cantilli, E.J., "Improving Transportation of Hazardous Materials Through Risk Assessment and Routing", Transportation Research Board, No PB-86-112471/XAB; TRB/TRR-1020, 1985.

6. Batta, R., Chiu, S.S., "Optimal Obnoxious Paths on a Network: Transportation of Hazardous Materials", Operations Research, Cilt 36, No 1, 84-92, 1988.

7. ReVelle, C., Cohon, J., Shobrys, D., "Simultaneous Siting and Routing in The Disposal of Hazardous Wastes", Transportation Science, Cilt 25, No 2, 138-145, 1991.

8. Abkowitz, M., Lepofsky, M., Cheng, P., "Selecting Criteria for Designating Hazardous Materials Highway Routes", Transportation Research Record, No 1333, 30-35, 1992.

9. Sivakumar, R.A., Batta, R., Karwan, M.H., “A Network-Based Model for Transporting Extremely Hazardous Materials", Operations Research Letters, Cilt 13, No 2, 85-93, 1993.

10. Sivakumar, R.A., Batta, R., "The VarianceConstrained Shortest Path Problem", Transportation Science, Cilt 28, No 4, 309-316, 1994.

11. Erkut, E., Verter, V., "Modeling of Transport Risk for Hazardous Materials", Operations Research, Cilt 46, No 5,625-642, 1998.

12. Bonvicini, S., Leonelli, P., Spadoni, G., "Risk Analysis of Hazardous Materials Transportation: Evaluating Uncertainty by Means of Fuzzy Logic", Journal of Hazardous Materials, Cilt 62, No 1, 59-74, 1998.

13. Erkut, E., Ingolfsson, A., "Catastrophe Avoidance Models for Hazardous Materials Route Planning", Transportation Science, Cilt 34, No 2, 165-179, 2000.

14. Barilla, D., Leonardi, G., Puglisi, A., "Risk Assessment for Hazardous Materials Transportation", Applied Mathematical Sciences, Cilt 3, No 46, 2295-2309, 2009.

15. Jassbi, J., Makvandi, P., "Route Selection Based on Soft MODM Framework in Transportation of Hazardous Materials", Applied Mathematical Sciences, Cilt 4, No: 63, 3121-3132, 2010.

16. Lovett, A.A., Parfitt, J.P., Brainard, J.S., "Using GIS in Risk Analysis: A Case Study of Hazardous Waste Transport", Risk Analysis, Cilt 17, No 5, 625-633, 1997.
17. Zhang, J.J., Hodgson, J., Erkut, E., "Using GIS to Assess The Risks of Hazardous Materials Transport in Networks", European Journal of Operational Research, Cilt 121, No 2, 316-329, 2000.

18. Verter, V., Kara, B.Y., "A GIS-based Framework for Hazardous Materials Transport Risk Assessment", Risk Analysis, Cilt 21, No 6, 1109-1120, 2001.

19. Ümit, H., Kara, B.Y., "Büyük Ölçekli Bir Tehlikeli Madde Taşımacılığının Coğrafi Bilgi Sistemleri Tabanlı Analizi: Shell Türkiye Örneği”, Yöneylem Araştırma Dergisi, No 15, 2003.

20. Huang, B., "GIS-based Route Planning for Hazardous Material Transportation", Journal of Environmental Informatics, Cilt 8, No 1, 49-57, 2006.

21. Monprapussorn, S., Watts, D. J., Banomyong, R., "Sustainable Hazardous Materials Route Planning with Environmental Consideration", International Conference on the Role of Universities in Hands-On Education, Rajamangala University of Technology, Lanna, Chiang-Mai, Thailand, 24-29 Ağustos 2009.

22. Wessberg, N., Molarius R., Seppala, J., Koskela, S., Pennanen J., "Environmental Risk Analysis For Accidental Emissions", Journal of Chemical Health \& Safety, Cilt 15, No 1, 24-31, 2008.

23. Topuz, E., Talinli, İ., Aydın, E., "Integration of Environmental and Human Health Risk Assessment for Industries Using Hazardous Materials: A Quantitative Multi Criteria Approach for Environmental Decision Makers", Environment International, 37: 393-403, 2011.

24. Li, R., Leung, Y., Huang, B., Lin, H., "A Genetic Algorithm for Multiobjective Dangerous Goods Route Planning", International Journal of Geographical Information Science, Cilt 27, No 6, 1073-1089, 2013.

25. Petrol Sanayi Derneği, 2010 Yılı Sektör Raporu, PETDER, İstanbul, 2010.

26. Alp, E., "Risk-based Transportation Planning Practice Overall Methodology and A Case Example", INFOR, Cilt 33, No 1, 4-19, 1995.

27. Erkut, E., Tjandra, S. A., Verter, V., "Hazardous Materials Transportation", Handbook in OR \& MS, Elsevier B.V, Editör: C. Barnhart and G. Laporte, Cilt 14, No 9, 539-621, 2007.

28. Sherali, H.D., Brizendine, L.D., Glickman, T.S., Subramanian, S., "Low-probability Highconsequence Considerations in Routing Hazardous Materials Shipments", Transportation Science, No 31, 237-251, 1997.

29. Erkut, E., Ingolfsson, A., "Transport Risk Models for Hazardous Materials", Operations Research Letters, Cilt 33, No 1, 81-89, 2005.

30. Ak, R., Bozkaya, B., "A Proposed Risk Model and a GIS Framework for Hazardous Materials 
Transportation", IEEE Engineering Management Conference, IEMC Europe, 2008.

31. Huang, B., "A GIS-AHP Method for HAZMAT Route Planning with Consideration of Security", Environmental Informatics Archives, No 2, 818-830, 2004.

32. Huang, B., Cheu, R.L., Liew, Y.S., "GIS and Genetic Algorithms for HAZMAT Route Planning with Security Considerations", International Journal of Geographical Information Science, Cilt 18, No 8, 769-787, 2004.

33. Ruifang, M., "Environmental Risk Assessment Model on Dangerous Goods in Logistics", Logistics for Sustained Economic Development, 2026-2032, 2010.

34. Kara, B.Y., Erkut, E., Verter, V., "Accurate Calculation of Hazardous Materials Transport Risks", Operations Research Letters, Cilt 31, No 4, 285-292, 2003.

35. U.S. Department of Transportation, Emergency Response Guidebook, PHMSA, Washington DC, USA, 2008.

36. Gunasekera, M.Y., Edwards, D.W., "Estimating the Environmental Impact of Catastrophic Chemical Releases to the Atmosphere: An Index Method for Ranking Alternative Chemical Process Routes", Trans Institution of Chemical Engineers, No 81, 463-474, 2003.
37. Andersson, A.S., Tysklind, M., Fangmark, I., “A Method to Relate Chemical Accident Properties and Expert Judgements in Order to Derive Useful Information for the Development of Environment-Accident Index", Journal of Hazardous Materials, No 147, 524-533, 2007.

38. Rygnestad, H., "Integrating Environmental Economics and Policy Analyses in a Geographical Information System", SJFI, 4, 2000.

39. Liu, K. F. R., Liang, H. H., Yeh, K., Chen, C. W., "A Qualitative Decision Support for Environmental Impact Assessment Using Fuzzy Logic", Journal of Environmental Informatics, Cilt 13, No 2, 93-103, 2009.

40. Ashtakala, B., Member, ASCE, Eno, L. A., "Minimum Risk Route Model for Hazardous Materials", Journal of Transportation Engineering, September/October, 1996.

41. Saaty, T.L., "The Seven Pillars of the Analytic Hierarchy Process", Proceedings of the 15th Int'l Conf on Multiple Criteria Decision Making (MCDM), Springer, NY, 1-15, 2001.

42. Saaty T.L., "Rank From Comparisons and From Ratings in the Analytic Hierarchy/ Network Processes", European Journal of Operational Research, Cilt 168, No 2, 2006. 
